\title{
CRESCIMENTO DESORDENADO ÀS MARGENS DO RIO PERICUMÃ NO MUNICÍPIO DE PINHEIRO- MA
}

\author{
Lorena Cristina Silva Sousa - lores321@ @otmail.com \\ Faculdade Pitágoras
}

Francisco Wendell Dias Costa - geo.fwcosta@gmail.com

FCT/UNESP campus Presidente Prudente 


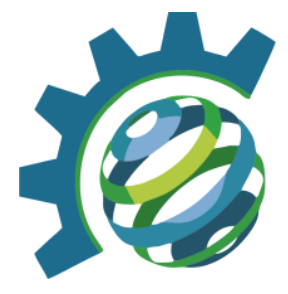

\section{RESUMO}

Aborda-se neste trabalho o crescimento desordenado as margens do Rio Pericumã no município de Pinheiro-Ma. O objetivo é analisar e diagnosticar os impactos gerados ao rio Pericumã, devido ao crescimento desordenado às margens do rio, disciplinar o uso e ocupação do solo, e a exploração dos recursos naturais. Os dados foram levantados a partir de trabalhos de campo nos dias 21/01/2017 e 22/01/2017 e registro fotográfico. Também se fez uso de imagens do Google Earth. Os resultados obtidos permitem inferir que os bairros Campinho e Matriz em uma margem de 5 (cinco) metros do canal do rio Pericumã encontra-se degradada, apresentando diversos impactos ambientais negativos relevantes no meio físico, biótico e antrópico, o que justifica a necessidade de sua recuperação, vista a importância dessa área na conservação e consequentemente na manutenção do equilíbrio hidrológico e ambiental da área. Os resultados também evidenciam que ao longo dos anos o rio vem sofrendo desmatamento da mata ciliar, aterramento das margens com ocupação irregulares para a construção de residências por moradores e assoreamento do seu leito. Dessa maneira é importante o reconhecimento dos impactos ambientais, quantificando-os, corrigindo-os e associando à população com ações de Educação Ambiental e, assim, propor possíveis soluções atenuantes, tais como: fiscalização mais atuante, proibição e punição para àqueles que praticarem desmatamento da mata ciliar, planejar o crescimento do município na vertical e não mais na horizontal, sobretudo nos bairros Campinho e Matriz.

Palavras-chave: Ocupação Irregular. Rio Pericumã. Impactos Ambientais.

\section{INTRODUÇÃO/OBJETIVO}

Segundo o Decreto No 11.900 de 11 de junho de 1991 cria, no Estado do Maranhão, a Área de Proteção Ambiental da Baixada Maranhense, compreendendo 03 (três) Sub-Áreas: Baixo Pindaré, Baixo Mearim-Grajaú e Estuário do Mearim-Pindaré - Baía de São Marcos incluindo a Ilha dos Caranguejos. O Art. $2^{\circ}$ desse Decreto estabelece que APA da BAIXADA MARANHENSE esta localizada em terrenos de formação geológica recente do Terciário e Quaternário, sujeita às inundações periódicas e invasões das marés, estendendo-se desde a região sublitorânea de Bacabal/Santa Inês (Sul) até o estuário do Mearim-Pindaré, na Baía de São Marcos, acompanhando o lado Oeste da Ilha do Maranhão, e terá uma área total de 


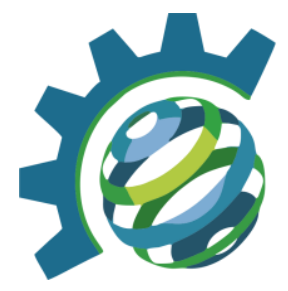

1.775.035,6 há, ficando subordinada administrativamente à Secretaria de Estado do Meio Ambiente e Turismo - SEMATUR.

A vegetação da Baixada é rica e variada, com a existência de desde manguezais, campos aluviais flúvio-marinhos, abertos, perto dos lagos, até densas florestas de galeria ao longo dos rios, com babaçuais formando "ilhas" nas terras mais altas, pouco atingidas pelas enchentes. Está presente na região uma rica fauna e flora aquática e terrestre, com diversas espécies raras, (MUNIZ, 2007, p. 05).

A região fica seis meses seca e seis meses alagadas. Na estação chuvosa, os rios e lagos transbordam deixando os campos inundados. Estes são transformados em extensos lagos rasos, onde se desenvolve essencialmente a pecuária bubalina e a pesca artesanal. Parte das águas é devolvida aos rios quando seus níveis baixam. (MUNIZ, 2007).

O Decreto $N^{\circ} 1.905$, DE 16 DE MAIO DE 1996, Promulga a Convenção sobre Zonas Úmidas de Importância Internacional, especialmente como Habitat de Aves Aquáticas, conhecida como Convenção de Ramsar, de 02 de fevereiro de 1971. A Área de Proteção Ambiental da Baixada Maranhense possui uma área de 1.775.035,9 ha, e estendem-se por 20 mil quilômetros quadrados nos baixos cursos dos rios Pericumã e Aura. Está localizada na região continental de oeste a sudeste da Baia de São Marcos e abrange 23 Municípios. Sua característica principal é a ocorrência de terras baixas, planas, inundáveis, "caracterizada por campo, mata de galeria, manguezais e bacias lacustres, foi incluída como sitio Ramsar devido ao alagamento de suas terras baixas, restando apenas terras firmes onde a presença de aves é abundante”. (GRANZIERA,2009, p.426).

O Município de Pinheiro está assentado predominantemente na Bacia do Rio Pericumã, sendo que sua sede se localiza nas proximidades da foz desse corpo hídrico, o que é um fator de exposição dos recursos nesta área (água, solo, matas ciliares e etc.), o que potencializa os impactos ambientais.

Com o crescimento e ocupação desordenada e irregular nas margens do rio Pericumã no Municio de Pinheiro, nota-se a incidência de impactos ambientais (desmatamento da mata ciliar, aterramento das margens com ocupação irregulares para a construção de residências por moradores e assoreamento do leito do rio) que são mais visíveis quando se percorre o trecho da rodovia estadual MA014 na entrada de Pinheiro, onde estão localizados os bairros do Campinho e Matriz. 


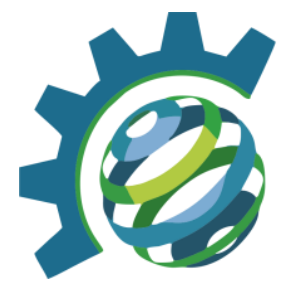

O objetivo é analisar e diagnosticar os impactos gerados ao rio Pericumã, devido ao crescimento desordenado às margens do rio, disciplinar o uso e ocupação do solo, e a exploração dos recursos naturais.

\section{METODOLOGIA}

Foram utilizados dados sobre desenvolvimento do município de Pinheiro colhidos no IBGE, elaboração de questionários destinados a moradores e comerciantes dos bairros Campinho e Matriz. Foram aplicados 20 (vinte) questionários para cada bairro, com 7 (sete) questões destinados aos moradores, nos dias 21/01/2017 e 22/01/2017.

Com o intuito de identificar os impactos ambientais no local, foi realizada uma avaliação preliminar, através de trabalho na área de estudo e registro fotográfico. Também se fez uso de imagens do Google Earth® $(2003$; 2017) para fazer comparação das alterações sofridas nas áreas de estudo.

Para melhor avaliação dos impactos, foi utilizado o método de matriz de agregação de impacto ambiental e foram adotadas várias categorias de parâmetros e intensidades desses efeitos, sendo: Classificação: Adversa (AD) ou Benéfica (BE); Incidência: Direto (DIR) ou Indireto (IND); Abrangência: local (LO) ou Regional (REG); Tempo: Passado (PA), Atual (AT) e Futuro (FU); Magnitude: Pequeno (PE); Médio (ME); Grande (GR). Adotadas várias categorias de parâmetro e intensidades desses efeitos, sendo conforme utilizada por (ROCHA, E. C; CANTO, J. L; PEREIRA, P. C. 2005).

\section{RESULTADOS E DISCUSSÃO}

O município de Pinheiro está localizado entre as latitudes $3^{\circ} 12^{\prime} 00^{\prime \prime} \mathrm{S}$ e $3^{\circ} 20^{\prime} 00^{\prime \prime} \mathrm{S}$ e longitudes $45^{\circ} 00^{\prime} 00^{\prime}, \mathrm{W}$ e $45^{\circ} 36^{\prime} 00^{\prime}, \mathrm{W}$, fazendo parte da mesorregião Norte Maranhense e de sua subdivisão denominada Microrregião da Baixada Maranhense (UEMA, 2002). Está situado a uma distância de $240 \mathrm{~km}$ de São Luís, apresentando uma altitude média de $14 \mathrm{~m}$, o município tem uma área total de $1.559 \mathrm{~km}^{2}$, com uma densidade demográfica de 51,67 hab./km² (IBGE, 2010) e principal via de acesso é a MA014. 

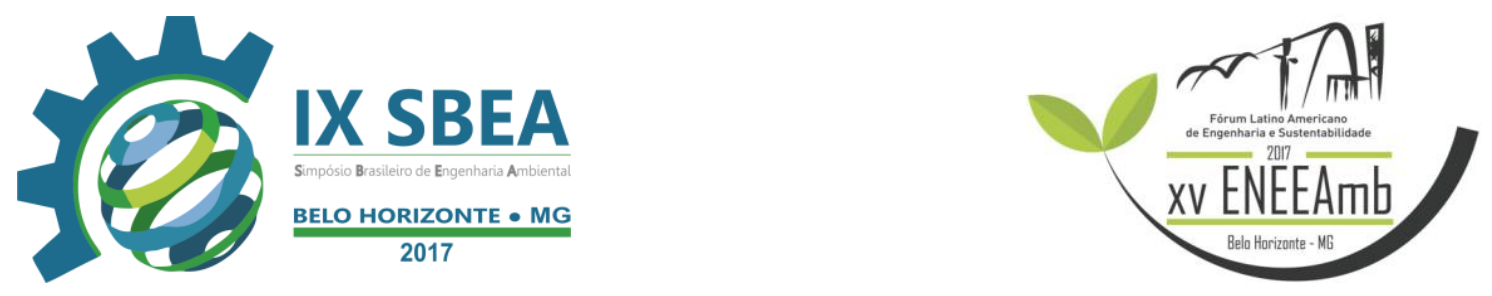

Essa região possui características fisiográficas marcantes como terras baixas, planas, inundáveis, caracterizada por campo, mata de galeria, manguezais e bacias lacustres. Solo argiloso, pouco consolidado com grande retenção de água. Na época das chuvas, de dezembro a julho, os campos baixos ficam alagados, restando ilhas de terras firmes. (RAMSAR, 2013)

O município de Pinheiro como a maioria das cidades do Brasil, não possuem tratamento de efluentes, o esgoto passa na rua na frente das residências e é despejado no rio Pericumã, com isso, sofre grande descarga de efluentes de forma in natura constantemente.

A área escolhida para o desenvolvimento deste foram os bairros Campinho e Matriz (Figura 1), pois estão sofrendo constantes mudanças na sua paisagem por vários motivos: crescimento populacional, comercial e residencial, gerando impactos ambientais constantes nas margens do rio Pericumã, pelo despejo de efluentes e resíduos, aterramentos do rio sobre as margens assim soterramento da mata ciliar que é caracterizado como crime ambiental.

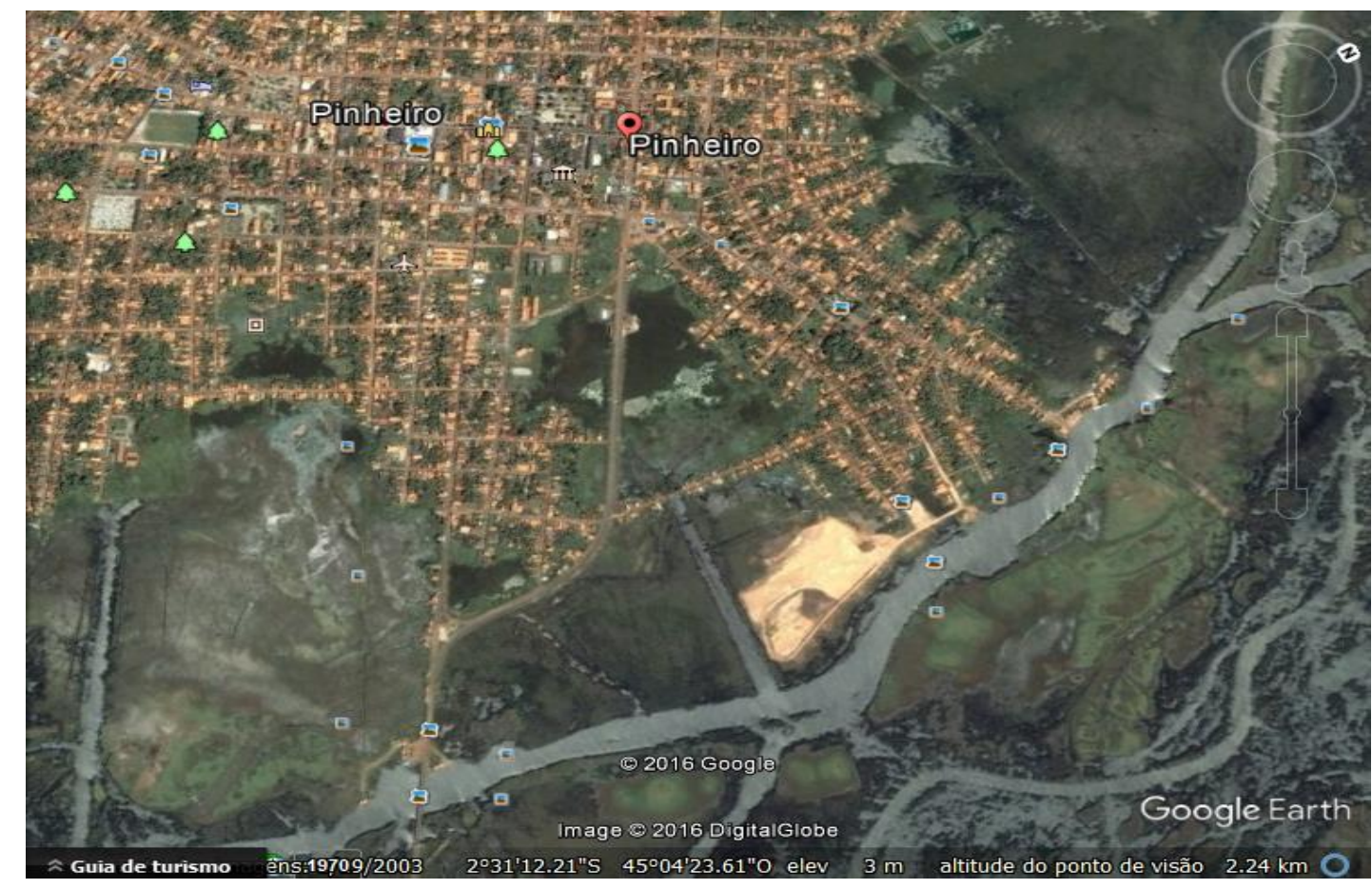

Figura 01: Localização dos Bairros Campinho e Matriz, Pinheiro-Ma Fonte: Google Earth

Ao longo dos anos o rio vem sofrendo com a constante prática do aterramento das margens para a construção de residências por moradores e vem se agravando, pois até prédios 


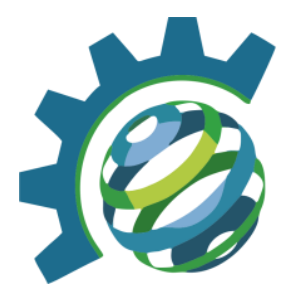

públicos (Rodoviária do Município, APA). Mostrando-se contraditório já que por lei a área em questão é uma APA da Baixada Maranhense e foi verificada a retirada da mata ciliar além desses impactos tem a questão do esgoto da cidade que vai para o rio sem tratamento e a grande quantidade de resíduos solidos que é jogando pela população mesmo passando os coletores nas ruas existe esse mau abito muitas das vezes por falta de conhecimento que aquele mal pode causar ao meio ambiente.

Portanto, nota-se que o rio Pericumã que abastece a cidade está em sérios apuros e que por fim a comunidade Pinherense e os órgãos responsáveis pelo resíduo da cidade (Prefeitura de Pinheiro) e abastecimento (CAEMA) que está causando esse dano vão sofrer adiante com as mazelas que esses impactos estão causando ao espaço em questão.

Um dos benefícios visados com a criação da APA em um dos bairros foi o lazer, a recreação, moradia e o crescimento da economia do local. O crescimento na área de estudo se agravou com o decorrer dos anos, pois, essa região fica na parte central, onde o fluxo de pessoas e de renda é maior, com isso as pessoas não querem se deslocar para outras extremidades do município, sendo que há muitas áreas que não são alagadas no município, que poderiam ser ocupadas e transformadas em bairros, porém ficam distante da área central do município.

Notou-se que a população que reside no bairro Campinho em uma margem de 5 metros do canal do Rio Pericumã a mais de 10 anos são pessoas que dependem do rio para sua subsistência, pois vivem da pesca, agricultura e de pequena criação de animais, já os moradores que residem a menos de 5 (cinco) anos, utilizam o rio apenas para abastecimento e lazer. Portanto notou-se que as principais rendas são pesca e agricultura das famílias que está há mais tempo e de outros comércios e funções não relacionadas ao rio Pericumã, o bairro possui infraestrutura, pois fica na região central do município com coleta de resíduos, iluminação pública, asfaltamento nas vias principais e abastecimento de água. O bairro é autossuficiente possui posto de saúde, transporte público, policiamento, escolas e creches os coletores passam normalmente 3 (três) vezes na semana.

No Bairro Matriz, a maioria mais de $50 \%$ reside a mais de 10 anos no local e dependem dos recursos do rio Pericumã. A maioria dos moradores que estão à margem de 5 metros do canal do rio Pericumã são pescadores e criadores de animais de pequeno porte como galinhas, porcos, patos, cabra e outros sendo criados no campo, pois o quintal desses 


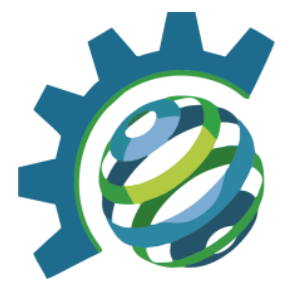

moradores é rio, as ruas possuem infraestrutura com coleta de resíduos 2 vezes na semana porém alguns moradores ainda não aderiram a essa pratica de guardar seus resíduos para ser levado no dia que o coletou for passar, infelizmente ainda é adotado uma pratica de atear fogo nos resíduos no quintal (rio Pericumã).

O Bairro Matriz é autossuficiente, pois tem posto de saúde, mercados e feiras, policiamento (parcialmente, ainda é falho queixa dos moradores referente a segurança), transporte publico e escolas e creches. Os impactos gerados são visíveis: loteamento das margens do rio sendo que é área de preservação permanente, matas ciliares sendo soterradas por solo incompatíveis com o solo dos campos das áreas alagadas protegidas por lei, porém no município de Pinheiro nem os órgãos competentes estão respeitando as leis e as executando.

Após a listagem dos impactos sobre os diferentes componentes do ambiente, separados aqui em meio físico, meio biótico e meio antrópico, foi feita uma breve discussão, destacando-se os impactos de maior relevância. (Tabela $01)$.

Tabela 01: Avaliação de Impactos no Rio Pericumã

Fonte: o autor (2017).

\begin{tabular}{|c|c|c|c|c|c|c|c|c|c|c|c|c|c|c|}
\hline \multicolumn{15}{|c|}{ Avaliação de Impacto Ambiental as Margens do Rio Periumã - Pinheiro -MA } \\
\hline \multirow{2}{*}{\multicolumn{3}{|c|}{ IMPACTOS }} & \multicolumn{2}{|c|}{ Classificação } & \multicolumn{2}{|c|}{ Incidência } & \multicolumn{2}{|c|}{ Abrangência } & \multicolumn{3}{|c|}{ Tempo } & \multicolumn{3}{|c|}{ Magnitude } \\
\hline & & & AD & BE & DIR & IND & LO & REG & PA & AT & FU & PE & ME & GR \\
\hline \multirow{5}{*}{ 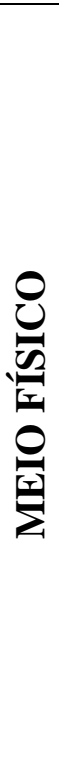 } & \multirow{2}{*}{$\begin{array}{l}0 \\
1 \\
0 \\
0\end{array}$} & $\begin{array}{c}\text { Escoamento } \\
\text { Superficial }\end{array}$ & $\mathbf{X}$ & & & $\mathbf{x}$ & $\mathbf{x}$ & & & $\mathbf{x}$ & & & $\mathbf{x}$ & \\
\hline & & $\begin{array}{c}\text { Erosão e } \\
\text { Instabilidade }\end{array}$ & $\mathbf{x}$ & & $\mathbf{x}$ & & $\mathbf{x}$ & & & $\mathbf{x}$ & & & & $\mathbf{x}$ \\
\hline & \multirow{2}{*}{ 岁 } & $\begin{array}{l}\text { Despejo de } \\
\text { Efluentes }\end{array}$ & $\mathbf{x}$ & & & & & $\mathbf{x}$ & $\mathbf{x}$ & & & & & $\mathbf{x}$ \\
\hline & & $\begin{array}{c}\text { Resíduos } \\
\text { Sólidos }\end{array}$ & $\mathbf{x}$ & & $\mathbf{x}$ & & & $\mathbf{x}$ & & $\mathbf{x}$ & & & & $\mathbf{x}$ \\
\hline & $\frac{\mathscr{C}}{4}$ & $\begin{array}{c}\text { Material } \\
\text { Particulado } \\
\text { Suspenso }\end{array}$ & $\mathbf{x}$ & & & $\mathbf{x}$ & & $\mathbf{x}$ & $\mathbf{x}$ & & & $\mathbf{x}$ & & \\
\hline
\end{tabular}




\begin{tabular}{|c|c|c|c|c|c|c|c|c|c|c|c|c|c|}
\hline \multirow{4}{*}{ 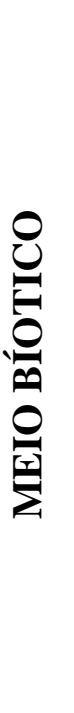 } & \multirow{2}{*}{ 岁 } & $\begin{array}{c}\text { Caça } \\
\text { predatória de } \\
\text { Aves }\end{array}$ & $\mathbf{x}$ & & $\mathbf{x}$ & & $\mathbf{X}$ & & $\mathbf{x}$ & & & $\mathbf{x}$ & \\
\hline & & $\begin{array}{c}\text { Introdução de } \\
\text { Animais } \\
\text { Domésticos }\end{array}$ & $\mathbf{x}$ & & & $\mathbf{x}$ & $\mathbf{x}$ & & $\mathbf{x}$ & & $\mathbf{x}$ & & \\
\hline & \multirow[b]{2}{*}{ 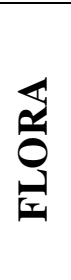 } & Mata Ciliar & $\mathbf{x}$ & & $\mathbf{x}$ & & $\mathbf{x}$ & & & $\mathbf{x}$ & & & $\mathbf{x}$ \\
\hline & & $\begin{array}{c}\text { Diminuição/ } \\
\text { Perda de } \\
\text { Biodiversidade. }\end{array}$ & $\mathbf{x}$ & & $\mathbf{x}$ & & $\mathbf{x}$ & & $\mathbf{x}$ & & & & $\mathbf{x}$ \\
\hline \multirow{2}{*}{$\stackrel{0}{\underline{0}}$} & \multirow{2}{*}{ 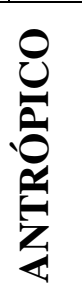 } & $\begin{array}{l}\text { Ocupação } \\
\text { Irregular }\end{array}$ & $\mathbf{X}$ & & $\mathbf{X}$ & & & $\mathbf{x}$ & $\mathbf{X}$ & & & & $\mathbf{X}$ \\
\hline & & $\begin{array}{c}\text { Recreação e } \\
\text { Lazer na APA }\end{array}$ & & $\mathbf{x}$ & & $\mathbf{x}$ & $\mathbf{x}$ & & $\mathbf{x}$ & & $\mathbf{x}$ & & \\
\hline
\end{tabular}

\subsection{Impactos ao Meio Físico}

Foi observado avanço do processo erosivo e um assoreamento do canal do rio, o que pode ter ocorrido devido a descarrega de sedimentos que foram jogadas na margem do rio para a construção da APA e foi agravado em função dos efeitos do escoamento superficial e de um deficiente sistema de drenagem pluvial (Figura 02). 

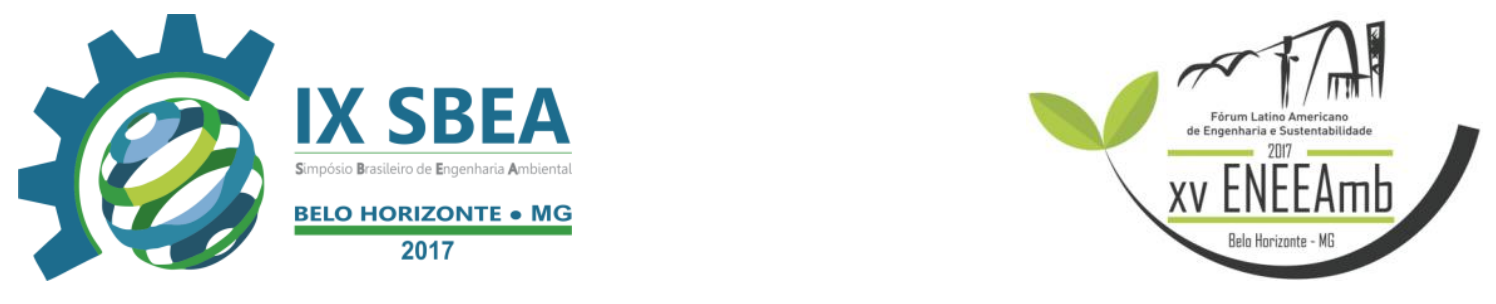

Figura 02: Erosão das margens e assoreamento do rio Pericumã

Fonte: Registro de Pesquisa (2017).

\subsection{Impacto do Meio Biótico}

Foi constatada alteração do ecossistema natural, com grande prevalência de animais domésticos (bubalinos, suínos, aves, cachorros, gatos) pelo fato de as pessoas criarem seus animais no campo livremente ocasionando impactos no rio como pisoteamento, compactação do fundo do rio, assim, alteram o funcionamento do ecossistema. (Figura 03).

Figura 03. Bubalinos no rio Pericumã

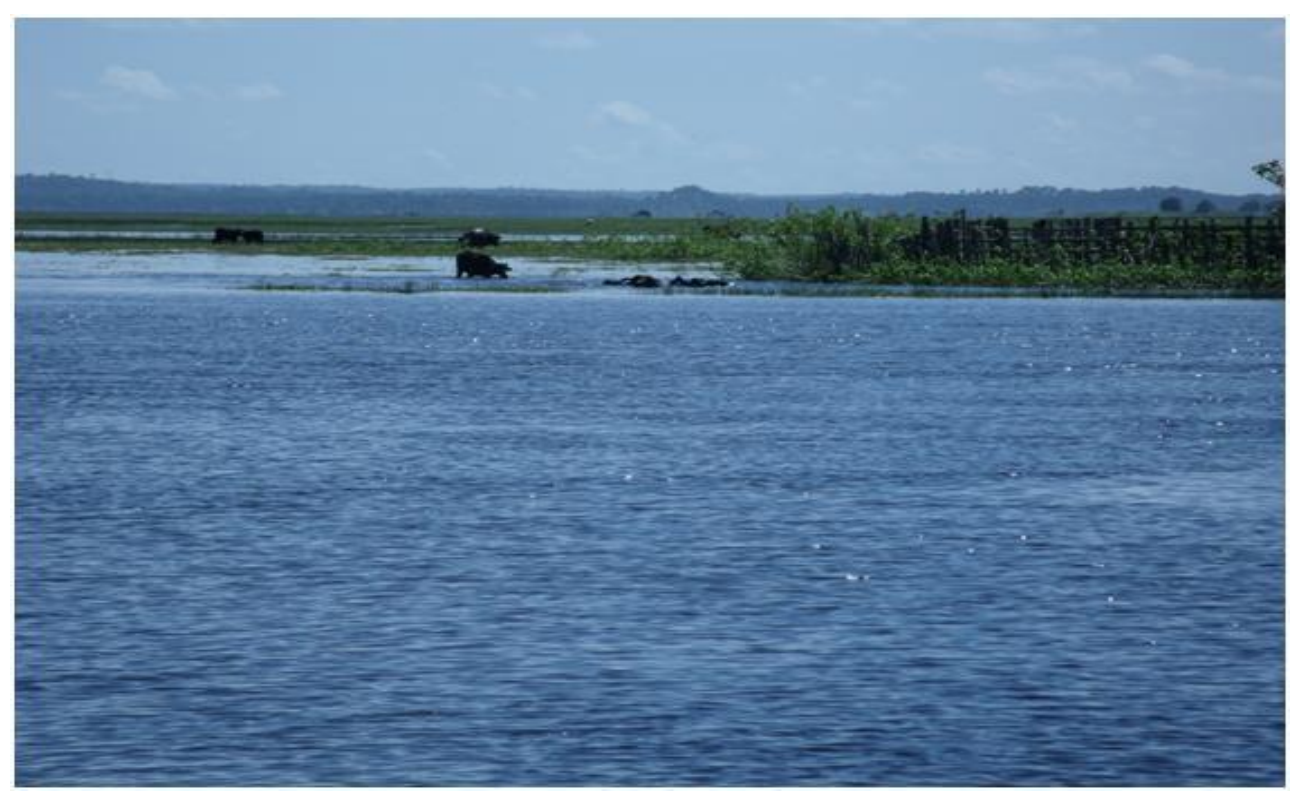

Fonte: Blog Pinheiro em Pauta (2017).

\subsection{Impacto Meio Antrópico}

Foi observado que moradores utilizam a área para a ocupação irregular, já que as casas estão localizadas nas margens do rio, sendo que os quintais de suas casas são o rio Pericumã que é uma área de APP. Cabe ao poder público a responsabilidade de fiscalizar e inibir ocupações irregulares em Áreas de Preservação Permanente urbana (Figuras 04 e 05). 

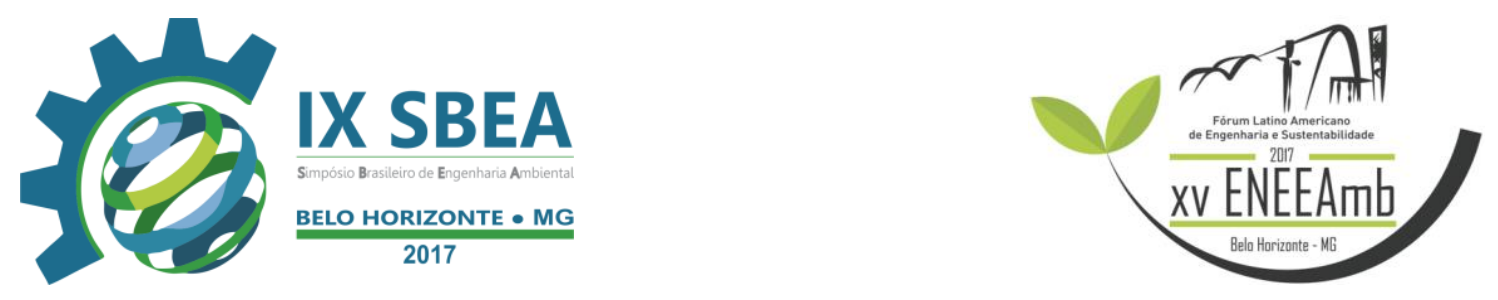

Figura 04: ocupação irregular Bairro Campinho, Pinheiro-MA

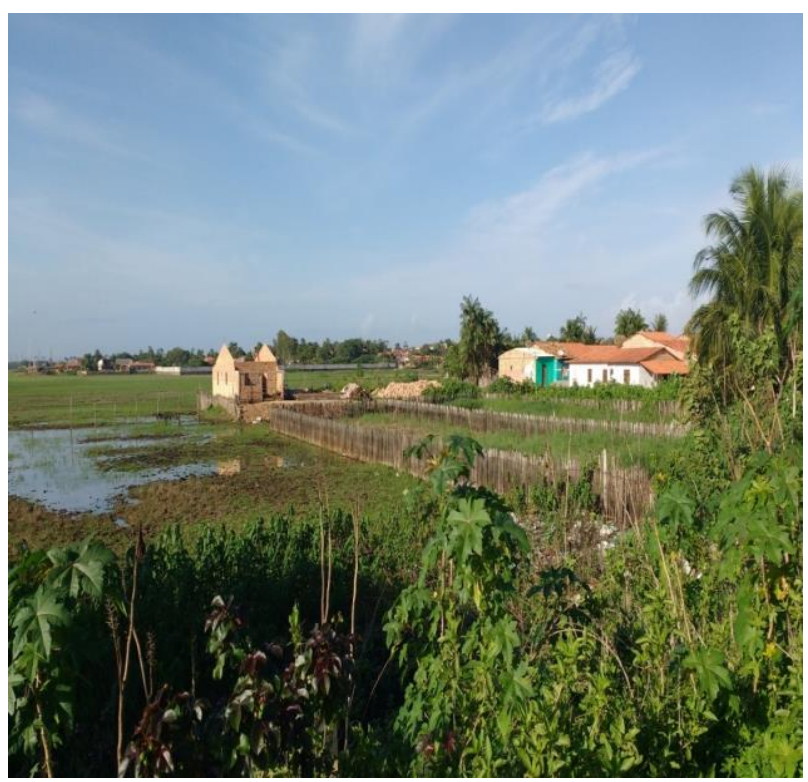

Figura 05: ocupação irregular Bairro Matriz, Pinheiro-MA

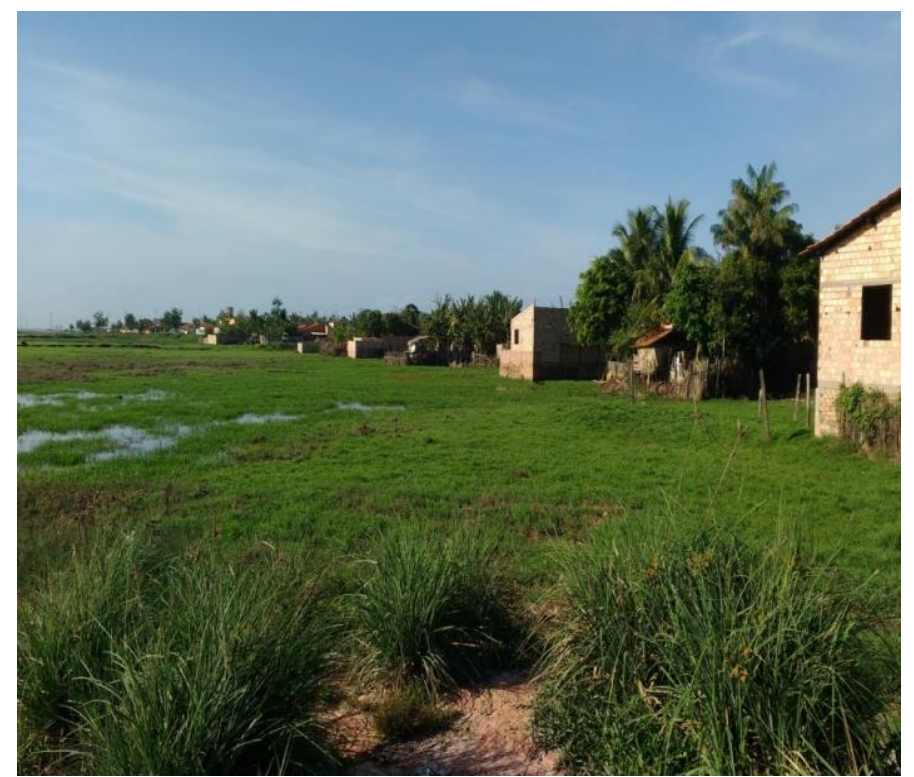

Fonte: Registro de Pesquisa (2017).

Fonte: Registro de Pesquisa (2017).

\section{CONCLUSÕES/RECOMENDAÇÕES}

Conclui-se que as margens do rio Pericumã na entrada do município de Pinheiro pela MA 014 estão sofrendo impactos constantemente, foi visto placas de vende-se em supostos lotes dentro do campo, sobretudo no período da estiagem. Neste período foram constatados construções de moradias, prédios públicos e outras construções (casa de evento, motel, bares).

Sabe-se que não haverá como remover as pessoas desse trecho, porém pode-se inibir o avanço dessas construções. Foi notado que no período da estiagem havia casas construídas a menos de 1 (um) metro de distancia do canal do rio. Com o crescimento da cidade provocou construções irregulares, soterramento das matas ciliares que ficavam as margens do rio por pessoas que possuem renda suficiente para adquirir um terreno em outras localidades do município que não sejam nas áreas alagadas, falta fiscalização dos órgãos competentes do município de Pinheiro e do estado.

Possíveis soluções a ser tomadas: a proibição e fiscalização para que não haja mais o soterramento do rio, atenuar o crescimento da cidade na horizontal nos bairros campinho e _matriz. Dessa maneira é de grande importância o reconhecimento dos impactos ambientais, 

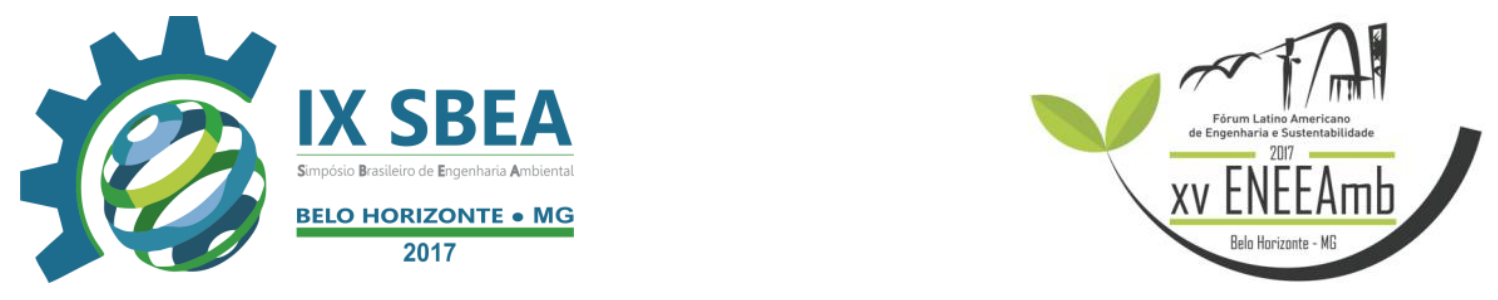

quantificando-os e corrigindo-os para se tentar recuperar estas áreas. É importante associar a população com ações de educação ambiental.

\section{REFERÊNCIAS BIBLIOGRÁFICAS}

BRASIL. DEC 1.905/1996 DE 16 DE MAIO 1996. Promulga a Convenção sobre Zonas Úmidas de Importância Internacional, especialmente como Habitat de Aves Aquáticas, conhecida como Convenção de Ramsar, de 02 de fevereiro de 1971. Disponível em: < http://www.planalto.gov.br/ccivil_03/decreto/1996/D1905.htm >. Acesso em: 27 de janeiro de 2017.

ESTADO DO MARANHÃO. DECRETO No 11.900 DE 11 DE JUNHO DE 1991. Disponivel em: <https://documentacao.socioambiental.org/ato_normativo/UC/303_20100823_145738.pdf $>$. Acesso em 28 de Janeiro de 2017.

GRANZIERA, Maria Luíza Machado. Direito Ambiental. São Paulo: Atlas, 2009. Acesso em: 20 de Janeiro de 2017.

IBGE - Instituto Brasileiro de Geografia e Estatísticas. Cidades - censo 2010. Disponível em:

<http://cidades.ibge.gov.br/xtras/perfil.php?lang=\&codmun=210860\&search=maranhao|pinhe iro|infograficos:-informacoes-completas>. Acesso em 28 de janeiro de 2017.

MMA - Ministério do Meio Ambiente. Disponível em: http://www.mma.gov.br/estruturas/205/_arquivos/apa_baixada_205.pdf.. >. Acesso em 28 de janeiro de 2017.

MUNIZ, Lenir Moraes. A criação de Búfalos na Baixada Maranhense: uma análise do desenvolvimentismo e suas implicações sócio-ambientais. III jornada internacional de políticas públicas, 2007, p.1-6. Disponível em : http://www.joinpp.ufma.br/jornadas/joinppIII/html/Trabalhos/EixoTematicol/Eixo\%209\%20a 117d7fcc8043a5882d91Lenir\%20Moraes\%20Muniz.pdf Acesso em : 30 de Janeiro de 2017.

ROCHA, E. C; CANTO, J. L; PEREIRA, P. C. Avaliação de impactos ambientais nos países do MERCOSUL. Ambiente e Sociedade. São Paulo, v. 8, n. 2, p. 148-160, jul./dez. 2005.

Sitio Ramsar, APA da Baixada Maranhense - MA, 2013: Planejamento para o Sucesso de Conservação. Disponível em: file:///C:/Users/Marcelo/Downloads/baixada_maranhense.pdf. Acesso em: 22/05/2017.

UEMA. Atlas do Maranhão. São Luís - MA: GEPLAN, 2002. Disponível em: < http://www.bellalex.net/arquivos/studio-idro-geologico-climatico-ed-altro.pdf $>$. Acesso em 28 de janeiro de 2017. 